\title{
Associação entre displasia e inflamação em queilite actínica
}

Primeira submissão em 22/06/12 Última submissão em 10/10/12 Aceito para publicação em 11/10/12 Publicado em 20/12/12

\section{Association between dysplasia and inflammation in actinic cheilitis}

Marcos Antonio Farias de Paiva'; Maria Sueli Marques Soares²; Cláudia Roberta L. Vieira de Figueiredo3; Aníbal Henrique Luna4; Victor Eric Nóbrega de Oliveira5; Ozawa Brasil Júnior ${ }^{5}$

\section{unitermos}

Queilite

Inflamação

Câncer bucal

\section{resumo}

Introdução: A queilite actínica pode se transformar em carcinoma espinocelular e há indícios de que componentes inflamatórios participam do processo de malignização, o que ressalta a importância de estudos envolvendo a presença de atipia celular e inflamação crônica nessa lesão. Objetivo: Avaliar histologicamente lesões de queilite actínica considerando os graus de displasia epitelial, intensidade do infiltrado inflamatório e possível correlação entre as variáveis. Material e método: Foram selecionados 45 blocos parafinados de lesões com diagnóstico clínico e histopatológico de queilite actínica e com condições para reavaliação histopatológica. Foi realizada análise histopatológica e classificação da displasia e do infiltrado inflamatório em grau leve, moderado ou grave. Os dados foram analisados por estatística descritiva e aplicou-se o teste quiquadrado e análise de variância (ANOVA), considerando $p<0,05$. Resultados: Dos casos de queilite actínica, 59,5\% (27) apresentavam algum grau de displasia, sendo $40 \%$ (18) displasia leve, $11,1 \%$ (5) moderada e $8,4 \%$ (4) grave. O carcinoma espinocelular ocorreu em $20 \%$ (9) dos espécimes. Todos os casos apresentaram algum grau de inflamação; $48,9 \%$ (22) eram infiltrado inflamatório leve, $20 \%$ (9), moderado e $31,1 \%$ (14), intenso. Houve associação estatisticamente significante entre o grau de displasia e a intensidade do infiltrado inflamatório, com $p=0,000$ ANOVA e $p=0,004$ quiquadrado. Conclusão: Os resultados indicam que a ocorrência de displasia e carcinoma espinocelular são frequentes na queilite actínica, e o processo inflamatório apresenta estreita relação com a progressão do agravamento da atipia epitelial. abstract

Introduction: Actinic cheilitis may undergo malignant transformation to squamous cell carcinoma. Furthermore, there is evidence that inflammatory components may be involved in this process, hence the importance of studies involving cellular atypia and chronic inflammation in this lesion. Objective: The aim of this study was to evaluate the histological features of actinic cheilitis considering the degree of dysplasia, the intensity of inflammatory infiltrate and the possible correlation between the variables. Material and methods: We selected 45 paraffin blocks of lesions with clinical and histopathological diagnosis of actinic cheilitis that enabled histopathological evaluation. The histopathological analysis was performed and the dysplasias and inflammatory infiltrates were classified into mild, moderate and severe. Data were analyzed through descriptive statistics, chi-square test and Analysis of variance (ANOVA), considering $p<0.05$. Results: $59.5 \%$ (27) of cases of actinic cheilitis showed some degree of dysplasia, from which $40 \%$ (18) presented mild dysplasia, $11.1 \%$ (5) moderate and $8.4 \%$ (4) severe. Squamous cell carcinoma occurred in $20 \%$ (9) of the specimens. All cases showed some degree of inflammation, from which $48.9 \%$ (22) showed mild inflammatory infiltrate, 20\% (9) moderate and 31.1\% (14) intense. There was a statistically significant association between the degree of dysplasia and the intensity of inflammatory infiltrate, namely ANOVA $p=0.000$ and chi-square $p=0.004$. Conclusions: The results indicate that the occurrence of dysplasia and squamous cell carcinoma are common in actinic cheilitis and the inflammatory process was closely related to the progression of epithelial atypia. key words

Cheilitis

Inflammation

Oral cancer

\footnotetext{
1. Doutor em Estomatologia; professor da Disciplina de Cirurgia Bucal da Universidade Federal da Paraíba (UFPB).

2. Doutor em Estomatologia; coordenador do Programa Integrado de Doutorado em Odontologia da UFPB/Universidade Federal da Bahia (UFBA)

3. Doutor em Patologia Oral; professor da Disciplina de Patologia Ceral da Faculdade de Odontologia da UFPB.

4. Doutor em Cirurgia Bucomaxilofacial; professor da Disciplina de Cirurgia bucal da UFPB.

5. Graduando em Odontologia da UFPB.
} 


\section{Introdução}

A queilite actínica (QA) é a principal lesão potencialmente maligna de lábio e pode sofrer transformação para carcinoma espinocelular (CEC). Vários autores ${ }^{(7,8,16)}$ acreditam que os mecanismos de malignização da lesão são favorecidos por componentes do processo inflamatório. A conexão entre inflamação e câncer foi mencionada em diversos estudos ${ }^{(3,7,8,11,16)}$ e há evidências de que o processo inflamatório atua na iniciação, promoção e progressão de tumores por meio de seus mediadores e efetores, contribuindo diretamente nas alterações do microambiente tumoral|(11). No entanto, esse tema continua gerando debate.

Em lesões actínicas de pele existe relação entre displasia e intensidade do processo inflamatório, tornando-se mais evidente com a progressão da displasia ${ }^{(3)}$. A QA apresenta processo etiopatogênico similar à ceratose actínica e pode ser considerada lesão análoga. Na QA, foi demonstrado aumento na quantidade de mastócitos ao se comparar lesões de QA e de CEC com o tecido normal, sugerindo uma possível participação da inflamação no processo de malignização da $Q A^{(8)}$. Existem relatos de que a intensidade do processo inflamatório na QA representa a única característica histológica associada ao grau de atipia epitelial e à presença de carcinoma invasivo de células espinhosas ${ }^{(14)}$.

Considerando o potencial de malignização da QA, sua etiologia e a frequente ocorrência de inflamação crônica foi proposto o presente estudo para avaliar histologicamente lesões de QA, analisando os graus de displasia, a intensidade do infiltrado inflamatório e a possível correlação entre essas variáveis.

\section{Metodologia}

Foram selecionados blocos parafinados referentes aos casos de lesões com diagnóstico clínico e histopatológico de QA, diagnosticados no período de 2005 a 2008, em um hospital público de referência do câncer em João Pessoa-PB. Para ser incluído no estudo, o espécime deveria estar em bom estado de conservação e em condições para novo corte e coloração para revisão histopatológica.

Foi realizado estudo retrospectivo, transversal. A amostra foi composta por 45 blocos selecionados e recortados em secções de $4 \mu \mathrm{m}^{2}$ de espessura para a obtenção de novas lâminas para coloração por técnica de rotina de hematoxilina e eosina (HE). A análise histopatológica dos espécimes selecionados foi realizada por dois patologistas de forma independente e as discordâncias resolvidas por consenso. A atipia celular e o grau displasia epitelial foram padronizados utilizando os critérios estabelecidos pela Organização Mundial da Saúde (OMS) ${ }^{(2)}$; a inflamação e a displasia classificadas em leve, moderada e grave. Os casos de carcinoma também foram registrados.

$\mathrm{Na}$ avaliação do grau do processo inflamatório das lesões estudadas, foi utilizada ocular de microscópio óptico OLYMPUS ${ }^{\circledast}$, com ampliação de 100x. Utilizou-se o método visual subjetivo para determinar a presença de infiltrado inflamatório e selecionar uma área do infiltrado para, em seguida, realizar análise por método objetivo, sempre desconsiderando as regiões de ulceração(5). A avaliação objetiva da intensidade do infiltrado inflamatório foi realizada por contagem de células ${ }^{(15)}$, usando um retículo acoplado à ocular do microscópio com ampliação de 400x. Dois patologistas realizaram a contagem em quatro campos e a leitura da média das células inflamatórias foi expressa em células $/ \mu \mathrm{m}^{2}$. Posteriormente, se utilizou o seguinte escore para classificar a intensidade do infiltrado inflamatório: de 1 a 5 células/ $\mu^{2}$ foi considerado infiltrado inflamatório leve; de 6 a $9 \mu \mathrm{m}^{2}$, infiltrado moderado; e de 10 ou mais células/ $\mu \mathrm{m}^{2}$, infiltrado intenso ${ }^{(15)}$.

Os dados foram tabulados e realizaram-se testes estatísticos no programa Statistical Package of Social Science (SPSS), sendo feita análise estatística descritiva, além da aplicação do teste qui-quadrado e da ANOVA, considerando significantes valores de $p<0,05$.

O estudo foi aprovado pelo Comitê de Ética do Centro de Ciências da Saúde da Universidade Federal da Paraíba (UFPB).

\section{Resultados}

Do total de 45 blocos parafinados com lesões de QA, $55,6 \%$ (25) eram de pacientes do sexo masculino e $44,4 \%$ (20), do feminino. A idade dos pacientes variou de 27 a 92 anos, com média de $60 \pm 17,1$ anos. Todos os pacientes eram brancos, $66,7 \%$ deles, agricultores e todas as lesões eram localizadas no lábio inferior.

A maioria dos espécimes de QA, 59,5\% (27), apresentava algum grau de displasia epitelial. A displasia leve ocorreu em $40 \%$ (18) dos casos; a moderada, em $11,1 \%$ (5); e a grave, em 8,4\% (4). Em 20\% (9) das lesões, o epitélio se apresentava sem displasia e em nove casos (20\%) eram CEC (Figuras 1, 2 e 3). O processo inflamatório das lesões estudadas era composto predominantemente por linfócitos, plasmócitos e macrófagos. Em todos os espécimes da amostra estudada 
foi observado algum grau de infiltrado inflamatório, sendo o infiltrado leve o mais frequente, com $48,9 \%$ (22), seguido do infiltrado intenso, com 31,1\%(14), e do moderado, com $20 \%$ (9) dos casos. A elastose solar esteve presente em $55,6 \%$ (25) das lesões estudados (Figura 2).

Considerando o grau de displasia epitelial e a presença de CEC, foi observada associação estatisticamente significante entre a gravidade dessas alterações e a intensidade do infiltrado inflamatório, com $p=0,000$ (ANOVA) e $p=$ 0,004 (quiquadrado) (Figura 4).

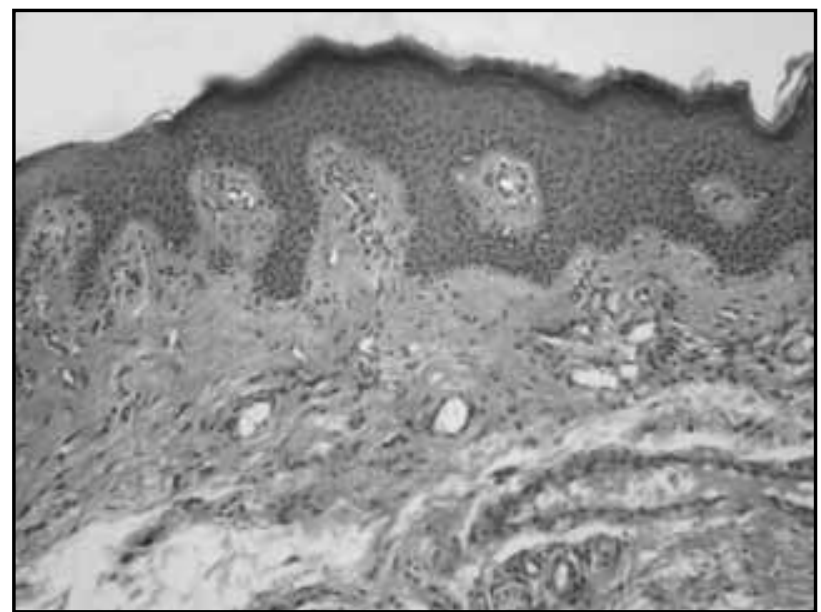

Figura 1 - Queilite actínica sem displasia epitelial. HE, 100x $H E$ : hematoxilina e eosina.

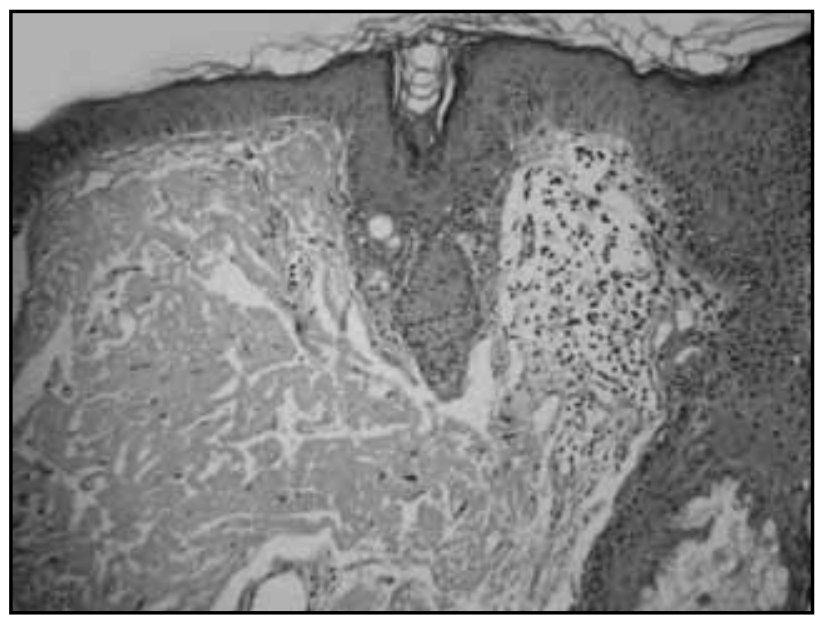

Figura 2 - Queilite actínica com displasia epitelial e elastose solar. HE, 100x $H E$ : hematoxilina e eosina.

\section{Discussão}

Há evidências de que o risco aumentado para transformação maligna em determinados tecidos tem relação com a inflamação associada a danos no ácido desoxirribonucleico (DNA) e à alteração na arquitetura do tecido pela ativação

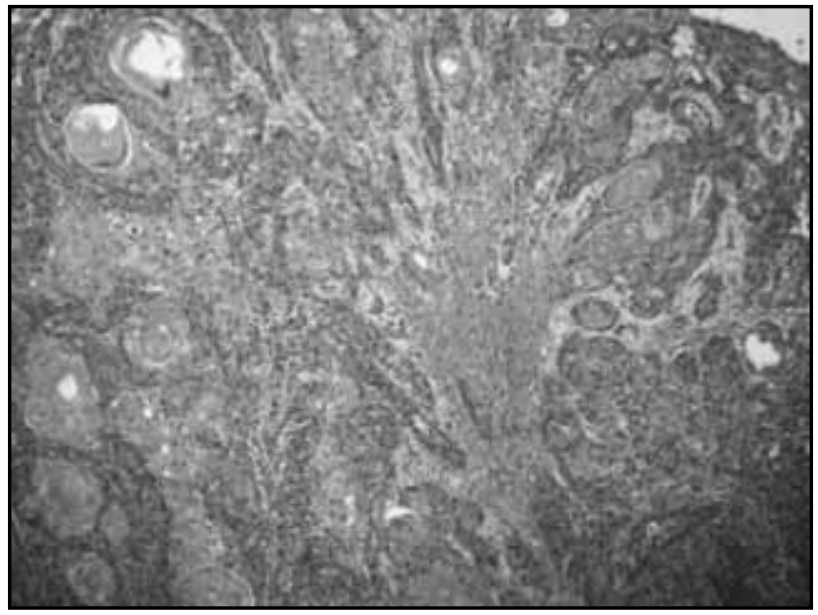

Figura 3 - Carcinoma espinocelular. HE, 100x $H E$ : hematoxilina e eosina.

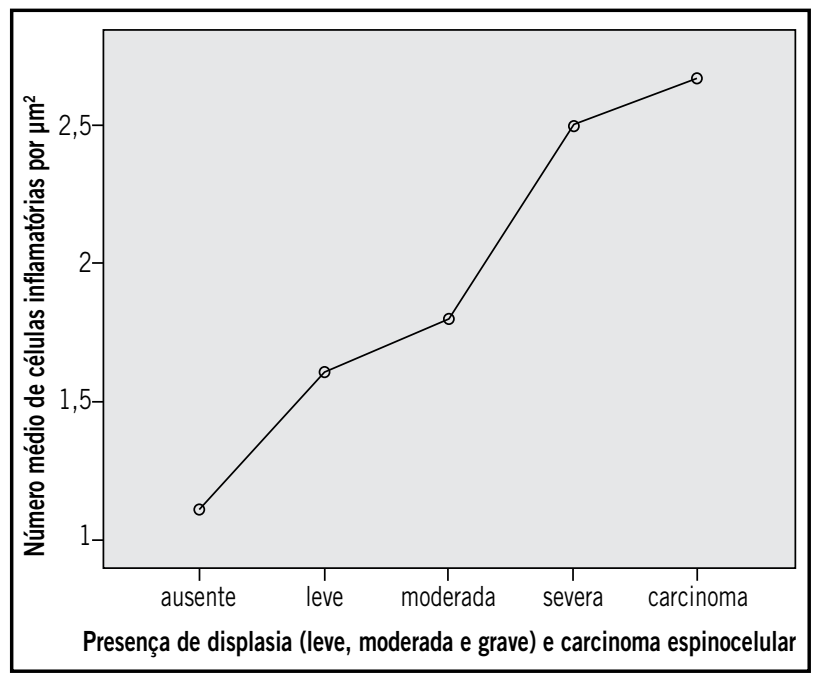

Figura 4 - Correlação entre intensidade do infiltrado inflamatório, presença de displasia e carcinoma em 45 pacientes com queilite actínica

de células e componentes do estroma capazes de influenciar a sobrevivência, crescimento, proliferação e diferenciação celular ${ }^{(13)}$. Na QA, frequentemente ocorre inflamação crônica provocada pelos raios ultravioleta que induzem a diminuição da reação imunológica local com alterações antigênicas; essas condições poderiam estar implicadas no processo de malignização da lesão. No presente estudo, todas as lesões foram localizadas no lábio inferior, corroborando o resultado de outro estudo ${ }^{(12)}$, entretanto divergindo de estudos que encontraram lesões de QA no lábio superior ${ }^{(10,14)}$.

A atipia dos ceratinócitos é uma importante característica histopatológica da QA que se instala gradualmente no epitélio. No presente estudo, esse dado foi constatado na maioria dos casos. Também foi observada a presença de displasia epitelial na maioria das lesões, o que foi ao encontro dos resultados de outros estudos ${ }^{(10,12)}$. No entanto, há trabalhos nos quais todos os casos de QA avaliados 
apresentavam algum grau de displasia epitelial ${ }^{(4)}$. Na amostra estudada, observou-se maior ocorrência de displasia leve e moderada, concordando com os resultados de estudos de vários autores ${ }^{(1,10,12,14)}$. Por outro lado, maiores percentuais de displasia moderada ou severa têm sido observados em casos de $Q A^{(4)}$. No presente estudo, notou-se elevada prevalência de CEC (20\%), estando de acordo com os resultados de outras pesquisas ${ }^{(10,12)}$ e ressaltando a importância da QA como lesão potencialmente maligna.

A presença do processo inflamatório foi um dado constante em todos os espécimes, confirmando os resultados de outros autores ${ }^{(4)}$. Constatou-se uma estreita relação entre a intensidade do processo inflamatório e o grau de displasia epitelial nas lesões estudadas. Esse dado sugere que a inflamação contribui para o agravamento da desorganização epitelial em lesões de QA; resultados similares foram anteriormente mencionados por outros autores ${ }^{(10,14)}$.

A relação entre processo inflamatório e displasia epitelial, cuja intensidade do processo inflamatório fica mais evidente com a progressão da displasia, sugere a participação ativa do processo inflamatório na desestruturação epitelial. Os autores afirmam que há evidente aumento do dano ao DNA celular durante a fase inflamatória(3). É importante ressaltar que a radiação ultravioleta tem função imunomoduladora local e sistêmica, o que pode causar imunossupressão local envolvendo a participação de células de Langerhans e células inflamatórias, como macrófagos e mastócitos ${ }^{(6,9)}$.

A frequente presença de inflamação em lesões de QA mostra que se deve dar maior atenção clínica para esse fenômeno e direcionar estudos que esclareçam a participação da inflamação na evolução dessa doença.

\section{Conclusões}

Considerando os resultados obtidos no presente estudo, pode-se concluir que a intensidade do infiltrado inflamatório na QA interfere na desorganização da arquitetura epitelial, característica da displasia, e contribui para o agravamento da lesão.

\section{Referências}

1. ARAÚJO, C. P. et al. Accumulation of CDla-positive Langerhans cells and mast cells in actinic cheilitis. J Mol Histol, v. 41, n. 6, p. 357-65, 2010.

2. BARNES, L. et al. World Health Organization Classification of tumours. Pathology and genetics of head and neck tumours. Lyon: IARC PRESS, 2005. 430 p.

3. BERHANE, T. et al. Inflammation is associated with progression of actinic keratoses to squamous cell carcinomas in humans. $\mathrm{Br} J$ Dermatol, v. 146, n. 5, p. 810-5, 2002.

4. CAVALCANTE, A. S.; ANBINDEL, A. L.; CARVALHO, Y. R. Actinic cheilitis: clinical and histological features. J Oral Maxillofac Surg, v. 66, n. 3, p. 498-503, 2008.

5. COSTA, N. L. et al. Density and migration of mast cells in lip squamous cell carcinoma and actinic cheilitis. Histol Histopathol, v. 24, p. 457-65, 2009.

6. DANDIE, G. W. et al. Effects of UV on the migration and function of epidermal antigen presenting cells. Mol mechanisms mutagen, v. 422, n. 1, p. 147-54, 1998.

7. DAWICKI, W.; MARSHALL, J. New and emerging roles for mast cells in host defense. Curr Opin Immunol, v. 19, n. 1, p. 31-8, 2007.

8. GOMES, A. P. N. et al. Comparative analysis of the mast cell density in normal oral mucosa, actinic cheilitis and lip squamous cell carcinoma. Braz Dent J, v. 19, n. 3, p. 186-9, 2008.

9. HART, P. H.; GRIMBALDESTON, M. A.; FINLAY-JONES, J. J. Sunlight immonosuppression and skin cancer: role of histamine and mast cells. Clin Exp Pharmacol Physiol, v. 28 , n. 1-2, p. 1-8, 2001.
10. KAUGARS, G. E. et al. Actinic cheilitis: a review of 152 cases. Oral Surg Oral Med Oral Pathol Oral Radiol Endod, v. 88, n. 2, p.181-6, 1999.

11. MANTOVANI, A. et al. Cancer-related inflammation. Nature, v. 454, n. 7203, p. 43-4, 2008.

12. MARKOPOULOS, A.; ALBANIDOU-FARMAKI, E.; KAYAVIS, I. Actinic cheilitis: clinical and pathologic characteristics in 65 cases. Oral Dis, v. 10, n. 4, p. 212-6, 2004.

13. MOGNETTI, B.; DI CARLO, F.; BERTA, G. N. Animal models in oral cancer research. Oral Oncol, v. 42, n. 5, p. 448-60, 2006.

14. NETO PIMENTEL, D. R. etal. Actinic cheilitis: histopathology and p53. J Cutan Pathol, v. 33, n. 8, p. 539-44, 2006.

15. PERES, F. F. G. Estudo clínico-histológico da queilite actínica crônico tratada por dois protocolos de laser de $\mathrm{CO}_{2}$ de baixa morbidade. 2006. (Tese de Doutorado) - Escola Paulista de Medicina da Universidade de São Paulo, São Paulo, 2006.

16. ROJAS, I. G. et al. Increased mast cell density and protease content in actinic cheilitis. J Oral Pathol Med, v. 33, n. 9, p. 567-73, 2004.
Endereço para correspondência

Maria Sueli Marques Soares

Rua Presidente Venceslau Braz, 770 - Bessa

CEP: 58035-220 - João Pessoa- PB 